\title{
Examining the nutritional value and effects of different floral resources in pumpkin agroecosystems on Bombus impatiens worker physiology
}

\author{
Erin D. Treanore, Anthony D. Vaudo, Christina M. Grozinger, \\ Shelby J. FLEISCHER \\ Department of Entomology, Center for Pollinator Research, Huck Institutes of the Life Sciences, Pennsylvania State \\ University, University Park, PA, USA
}

Received 10 August 2018 - Revised 28 February 2019 - Accepted 24 June 2019

\begin{abstract}
Floral enhancement schemes in agroecosystems are a common method to supplement bee dietary requirements, yet there is little information about how species used in these schemes influence bee physiology and how their nutritional value compares to the floral resources provided by the crop species. Here, we examined the pollen nutritional quality (macronutrient concentrations and protein:lipid ratio) of pumpkin (Cucurbita pepo, Cucurbitaceae), two species commonly used in enhancement schemes, Helianthus annuus (Asteraceae) and Crotalaria juncea (Fabaceae), a multifloral diet and an artificial diet. We tested effects of these diets on physiological characteristics of Bombus impatiens, a generalist pollinator. Bees performed best on real pollen diets, with consumption of $C$. juncea and multifloral pollen having the most pronounced effects on bee physiology. Our results underscore the importance of considering nutritional quality when selecting plant species for these schemes.
\end{abstract}

pollen nutrition / bumble bee physiology / floral rewards / agroecosystems / microcolonies

\section{INTRODUCTION}

Agricultural intensification can result in the loss of floral resources, a major factor underpinning declines of pollinator populations (Goulson 2010). One strategy to mitigate this is to augment floral resources in agriculturally intensive landscapes (Goulson et al. 2008). Floral enhancements are designed to support pollinators in systems where floral resources may otherwise be missing,

Electronic supplementary material The online version of this article (https://doi.org/10.1007/s13592-019-00668-x) contains supplementary material, which is available to authorized users.

Corresponding author: E. Treanore, ezt5142@psu.edu

Manuscript editor: David Tarpy reduced, or limited to a single agricultural species (Carvalheiro et al. 2012). By providing diverse assemblages of flowering resources, bees are able to gather sufficient quantities and quality of nectar; their primary source of carbohydrates necessary for flight and foraging (Brodschneider and Crailsheim 2010; Cnaani et al. 2006) and pollen; and their primary sources of lipids, proteins, sterols, and micronutrients (Brodschneider and Crailsheim 2010; Roulston and Cane 2000) to support maintenance of health and reproduction (Vaudo et al. 2015).

Consumption of nutritious pollen is critical for supporting bee health, development, and reproduction (Roger et al. 2017; Wright et al. 2018). In female bees, nutritious pollen is particularly important for ovarian activation and egg laying, as has been documented in Osmia sp. (Cane 2016), honey bees (Frias et al. 2016) and bumble 
bees (Duchateau and Velthuis 1989). In bumble bees, Bombus terrestris Linnaeus and B. impatiens Cresson, pollen consumption also is critical for larval development, survival, and adult size (Moerman et al. 2015; Sutcliffe and Plowright 1988, 1990). In honey bees, Apis mellifera Linnaeus, pollen diets support the development of hypopharyngeal glands (which produce brood food), synthesis of storage proteins, and adult bee longevity (Brodschneider and Crailsheim 2010; Crailsheim et al. 1992; Frias et al. 2016). Furthermore, pollen is important for improved defenses against parasites, pathogens, and pesticides. Pollen feeding in honey bees improves tolerance to pesticides (Schmehl et al. 2014), and consumption of more proteinaceous pollen has been linked with improved immunocompetence (Alaux et al. 2010). Bumble bees deprived of pollen and faced with an immune challenge showed reduced learning ability (Riddell and Mallon 2006) and queens exposed to the neonicotinoid, Imidacloprid, and limited to a monofloral diet showed reduced survival and decreased brood production (Leza et al. 2018).

Pollen from different plant species ranges widely in its nutritional content, varying from 2.5 to $61 \%$ in protein concentration (Roulston et al. 2000) and 1 to $20 \%$ in lipid concentration (Roulston and Cane 2000; Vaudo et al. 2016a). Pollen is the primary source of dietary sterols, which play an important role in hormone synthesis, development, and maintenance of cell membranes (Behmer and Nes 2003). Sterol levels in pollen also show considerable variation between plant species (Rasmont et al. 2005; Vanderplanck et al. 2014). Variation in the micro- and macronutrient levels of pollen can directly impact the physiology of the bees consuming them. For example, $B$. terrestris workers consuming pollen with a higher protein content produce larger offspring and exhibit reduced levels of oophagy (Génissel et al. 2002; Tasei and Aupinel 2008b). High levels of certain sterols (e.g., 24methylenechol/campesterol) improve reproductive performance in $B$. terrestris workers (Vanderplanck et al. 2014). In honey bees, protein-rich pollen is directly correlated with increased hypopharyngeal gland development and the expression levels of genes involved in regulating reproduction (Di Pasquale et al. 2013).
More recently, several studies have demonstrated that bees differentiate between pollen of different nutritional qualities and will preferentially collect/select resources that meet nutritional requirements. For example, nutritional deficits in honey bee colonies may be regulated by complementary foraging strategies, with evidence of honey bee workers changing their foraging dances depending on colony levels of omega 3 and 6 fatty acids (Zarchin et al. 2017). Levels of essential amino acids (EAA) also appear to be regulated, with free-flying honey bee workers selecting diets complementary to nutritional deficits of specific EAA's (Hendriksma and Shafir 2016). In bumble bees, B. impatiens workers show preference for pollen with specific protein:lipid ratios ( 5:1 P:L) when foraging among plant species and in lab-based pollen choice assays (Vaudo et al. 2016a). Individual B. terrestris workers in microcolonies continuously assess pollen quality and will repeatedly select pollen of higher protein content (Ruedenauer et al. 2016). Free foraging $B$. impatiens commercial colonies also demonstrate regulation of nutritional intake across varying landscapes (Vaudo et al. 2018).

In our study, we examined the nutritional composition of pollen of floral species available in a pumpkin (Cucurbita pepo) agricultural system in the Mid-Atlantic region and examined how different pollen qualities correlate with Bombus impatiens worker physiology. Bombus impatiens are generalist pollinators which contribute to pollination of several agricultural crops in this region, including pumpkins (Artz et al. 2011; McGrady 2018). The squash specialist, Eucera pruinosa, is also found in this system but would not benefit from floral enhancement schemes and thus was not considered for our studies. Furthermore, field observations have shown pumpkin (C. pepo ) is a less attractive pollen resource for $B$. impatiens when bull thistle (Cirsium vulgare) or nightshades (Solanum spp.) are present (Fleischer unpubl. data). While pumpkin nectar is known to have high-levels of amino acids, sucrose, and enzymatic activity (Nepi et al. 2011, 2012), these field observations suggest that the quality or composition of pumpkin pollen make it an undesirable resource for $B$. impatiens. 
Because of the hypothesized unattractive nature of pumpkin pollen to $B$. impatiens, providing a diverse assemblage of pollen-providing floral resources in pumpkin agroecosystems may be necessary to support these pollinators. Here, we examined the nutritional composition of pollen from pumpkin (Cucurbitaceae: Cucurbita pepo) and two plant species commonly used in floral enhancement schemes in pumpkin agroecosystems in the Mid-Atlantic, sunflower (Asteraceae: Helianthus annuus), and sunn hemp (Fabaceae: Crotalaria juncea). We also examined a multifloral mix of native Pennsylvanian flowers, an artificial honey bee diet, and a diet limited to sucrose syrup. To examine the correlation between these diets and $B$. impatiens worker physiology, we used microcolonies of three Bombus workers, a commonly used experimental approach to examine pollen nutritional quality (Regali and Rasmont 1995; Tasei and Aupinel 2008a). Using this approach, we examined (1) the effects of pumpkin pollen consumption on $B$. impatiens physiology, (2) how consumption of alternative pollen resources affects $B$. impatiens physiology, and (3) if there is a correlation between pollen P:L ratios and $B$. impatiens physiology. We compared oocyte size and the average weight change on a per bee basis. In each microcolony, we examined whether wax was produced by the adults, which is an important task for workers in their parental colonies. By examining these variables, we found differential importance and function of pollen macronutrients in microcolonies of $B$. impatiens workers.

\section{MATERIALS AND METHODS}

\subsection{Experimental design}

"Parental" B. impatiens colonies were purchased from Koppert Biological Systems (Howell, MI) and fed commercial sugar water ad libitum. Upon arrival, colonies were weighed and inspected for any visible markers of pathogens, e.g., deformed wings, and the presence of the queen. Colonies were held at approximately $30 \%$ humidity and $29^{\circ} \mathrm{C}$ for $48 \mathrm{~h}$ between colony arrival and the beginning of the experiment. Environmental conditions where parental colonies were kept were monitored using $\mathrm{HOBO}$
(Onset Corporation $^{\mathrm{TM}}$ ) data loggers and held at 30\% humidity and $30^{\circ} \mathrm{C}$.

The experiment was conducted twice: once in January 2016 and once in December 2016, in a complete randomized block design. Three different parental colonies were used per replicate, and for each microcolony, workers were randomly sampled from a single colony. Microcolonies of workers from each parental colony were distributed across the treatment groups. Parental colony was included in the statistical model and was not significant. In total, we had five pollen dietary treatments in January 2016 and six pollen dietary treatments in December 2016.

For the January 2016 trial, pollen from sunn hemp $(C$. juncea $)$ and sunflower $(H$. annuus $)$ was collected between September and October of 2015 by hand from flowers randomly selected in floral enhancement schemes at the Russell E. Larson Research and Education Center near Rock Springs, PA, and the Southeast Agricultural Research and Extension Center (SEAREC) in Landisville, PA. Plantings were of an average size of $1000 \mathrm{~m}^{2}$. Sunn hemp plants $(C$. juncea $)$ were cut and pollen collected using paintbrushes and forceps into sterile vials within $24 \mathrm{~h}$ of removal from the field. Sunflower (H. annuus) and pumpkin (C. pepo) pollen was collected directly into sterile vials from flowering plants in the field. For each floral species, a minimum of 30 different plants were used to source the pollen. After collection, vials were immediately frozen at $-20{ }^{\circ} \mathrm{C}$. Pumpkin (C. pepo) pollen for the January 2016 replicate was collected in Columbia County, PA in 2015.

For the December 2016 trial, sunn hemp (C. juncea), sunflower (H. annuus), and pumpkin (C. pepo ) pollen was collected from September to October of 2016 following the same protocol as above. Additionally, we created a multifloral pollen diet, which included pollen collected from pumpkin (C. pepo ) as well as four other common native plant species found in this region, Indian Blanket (Asteraceae: Gaillardia pulchella), Black-eyed Susan (Asteraceae: Rudbeckia hirta), Plains Coreoposis (Asteraceae: Coreopsis tinctoria), and Partridge Pea (Asteraceae: Chamaecrista fasciculata). The diet was comprised primarily of $G$. pulchella and C. tinctoria ( $\sim 65 \%$ by weight). Pollen from the multifloral 
diet was collected by hand, and all pollen was stored at $-20^{\circ} \mathrm{C}$ until the start of experiment.

We used queenless microcolonies for examining the effects of diet quality, following standardized protocols (Regali and Rasmont 1995; Tasei and Aupinel 2008a). Queenless bumble bee workers are able to produce haploid eggs, and when pollen and nectar are provided ad libitum, suppression of ovarian development by sister workers is thought to be reduced (Sibbald and Plowright 2013). Each microcolony was comprised of three similar-sized $B$. impatiens workers from the same queenright parental colonies placed in a $6.6 \times 8.3 \times 9.5-\mathrm{cm}$ Plexiglas vented chamber. Prior to adding the bee to the microcolony, each individual was chilled at $-20{ }^{\circ} \mathrm{C}$ until movement slowed, weighed (ML54 Analytical Balance, Mettler Toledo, Switzerland), and marked for individual identification (red, blue, or no color, TESTORS $\AA$ enamel marker (http://www.testors.com/). We placed 2-mL microcentrifuge tubes filled with a $50 \%$ sucrose solution with a hole bored in the tube for feeding through the top of the microcolonies; these sugar feeders were replaced daily.

Each of these treatments consisted of a total of 10 microcolonies fed a single pollen diet: (i) sunflower ( $H$. annuus), (ii) sunn hemp (C. juncea), (iii) pumpkin (C. pepo), (iv) an artificial protein diet designed for honey bees (MegaBee, San Diego, CA), and (v) sucrose syrup only; the multifloral diet treatment (vi) consisted of five microcolonies total. The January 2016 replicate was conducted with the sunflower ( $H$. annuus $)$, sunn hemp (C. juncea), pumpkin (C. pepo), artificial, and sucrose syrup diets. The December 2016 replicate included the above diets in addition to the multifloral diet. Microcolonies were provided with pollen ad libitum in a small dish in the microcolony. Two drops of sucrose syrup were added to the pollen in their respective microcolony containers to form a paste-like substance. Fresh pollen diet was added daily. The experiment ran for seven days which is sufficient time for Bombus workers to develop ovaries after removal from a queenright colony (Duchateau and Velthuis 1989). While it would have been desirable to allow the experiment to run longer, we were limited by the amount of pollen available. Furthermore, over longer periods of time in queenless conditions, all
B. impatiens workers fully develop their ovaries (Amsalem et al. 2015b), which would limit the ability to discern differences between treatments. Any bees that died during the course of the experiment were removed, and date of removal was noted. At the end of the seven days, all bees were once again immediately weighed and stored at $20{ }^{\circ} \mathrm{C}$ for dissection.

\subsection{Pollen nutritional analyses}

We used two methods to calculate the concentrations $(\mu \mathrm{g} / \mathrm{mg})$ of protein, lipid, and carbohydrates in the pollen: a Bradford assay to calculate the protein concentration and a modified assay from Van Handel and Day (1988) to calculate carbohydrate and lipid concentrations (Vaudo et al. 2016a). A detailed protocol can be found in the supplementary information. Approximately $10 \mathrm{mg}$ of each pollen treatment was needed for the combination of the lipid, carbohydrate, and protein assays.

\subsection{Measurements of bee physiology}

All bees that survived the entire experiment were examined for differences in mass $(\mathrm{g})$ over seven days, referred to as "weight change." Weight, head size, and marginal cell length are highly correlated in Bombus females (Shpigler et al. 2013; Yerushalmi et al. 2006), and because weight can be affected by nutrition, we decided it the best variable of these to examine. We assessed ovary development of each individual by measuring the average length $(\mathrm{mm})$ of the three largest terminal oocytes (one oocyte from each ovariole) using a Leica MZ6 microscope (Leica Microsystems Inc., Buffalo Grove, IL) under $\times$ 200 magnification, as in Amsalem et al. 2015a. Microcolonies were examined daily for the presence of wax structures (i.e., wax production) with photos taken from each individual microcolony at the end of the experiment. Because the bees often removed pollen from the feeding dishes without eating, we were unable to determine the total weight of pollen consumed. To verify pollen consumption occurred, we examined the midgut in a subset of individuals across all pollen-like treatments for the presence of pollen. 


\subsection{Data analyses}

We analyzed the effects of initial starting weight and treatment on survival using a Coxproportional hazard analysis. We then analyzed the effects of treatment and weight change (as a covariate) and the interaction of treatment and weight change on average oocyte size using a generalized linear model (GLM); note that oocyte size was not normally distributed (goodness of fit test $p<0.05)$. We also screened the effect of parental colony on overage oocyte size and weight change using Wilcoxon/Kruskal-Wallis and found it was not significant; thus, we did not include it in our final model.

For post-hoc analyses, we analyzed the effect of treatment on oocyte size and weight change using Wilcoxon method for pairwise comparisons and the effect of weight change on oocyte size using linear regression. We examined the presence or absence of wax structures in each microcolony at the end of the experiment and counted the number of microcolonies with wax out of the overall total to measure proportion. We analyzed if dietary treatment affected the production of wax using a nominal logistic regression and odds ratio test. We verified that paint marking did not have a significant effect on ovarian development using a Wilcoxon $t$ test (paint vs. no paint). All data analyses were conducted with JMP Pro v.14.0.0 Software (SAS Institute Inc.).

\section{RESULTS}

Our analysis of pollen quality (Table I) showed that sunn hemp (C. juncea) had the highest P:L ratio $(1.7: 1)$, and the multifloral diet had the lowest $(0.95: 1)$. Pumpkin (C. pepo) had the second highest P:L ratio (1.45:1). Sunflower (H. annuus ) had the highest amount of lipids as compared to any of the other diets and a P:L ratio of approximately $1: 1$.

In total, $92 \%$ of all bees survived the experiment (Table I), resulting in a sample size of at least 27 in all treatments (except the multifloral diet which was only included in the second replicate, and thus had a final sample size of 14 of 15 bees). We obtained final weight and oocyte size measurements from 152 bees across all treatments. We found no significant effect

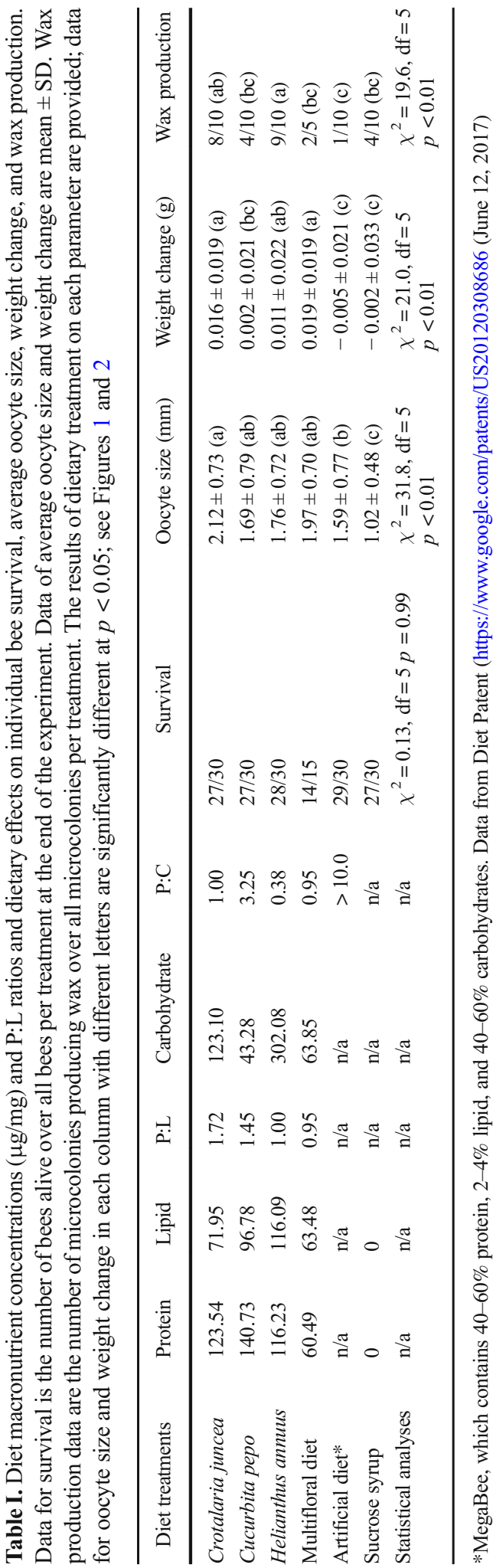


of treatment (Cox-proportional hazard $\chi^{2}=0.129$, $P=0.99)$ or initial starting weight (Cox-proportional hazard $\chi^{2}=0.08, p=0.76$ ) on the survival of the workers all our treatments. Paint marking also had no effect on oocyte development (Wilcoxon $t$ test $Z=0.22, p=0.8259)$ and parental colony did not have a significant effect on oocyte size $\left(\chi^{2}=5.5\right.$, $\mathrm{df}=5, p=0.36)$ or weight change $\left(\chi^{2}=3.3, \mathrm{df}=5\right.$, $p=0.65)$.

The GLM analysis showed that treatment (L-R $\left.\chi^{2}=29.85, \mathrm{df}=5, p<0.001\right)$ and weight change
(L-R $\left.\chi^{2}=16.82, \mathrm{df}=1, p<0.001\right)$, and the interaction of treatment and weight change, though marginal $\left(\mathrm{L}-\mathrm{R} \chi^{2}=10.54, \mathrm{df}=5, p=0.05\right)$, were significantly correlated with oocyte development (Table I; Figure 1a). Differences in oocyte size were significantly higher in bees that consumed C. juncea pollen relative to artificial diet, but no significant differences among bees that consumed pollen diets were found (Table I; Figure 1a). Thus, overall, pollen is a critical component in the diet of adult bumble bees for ovarian development
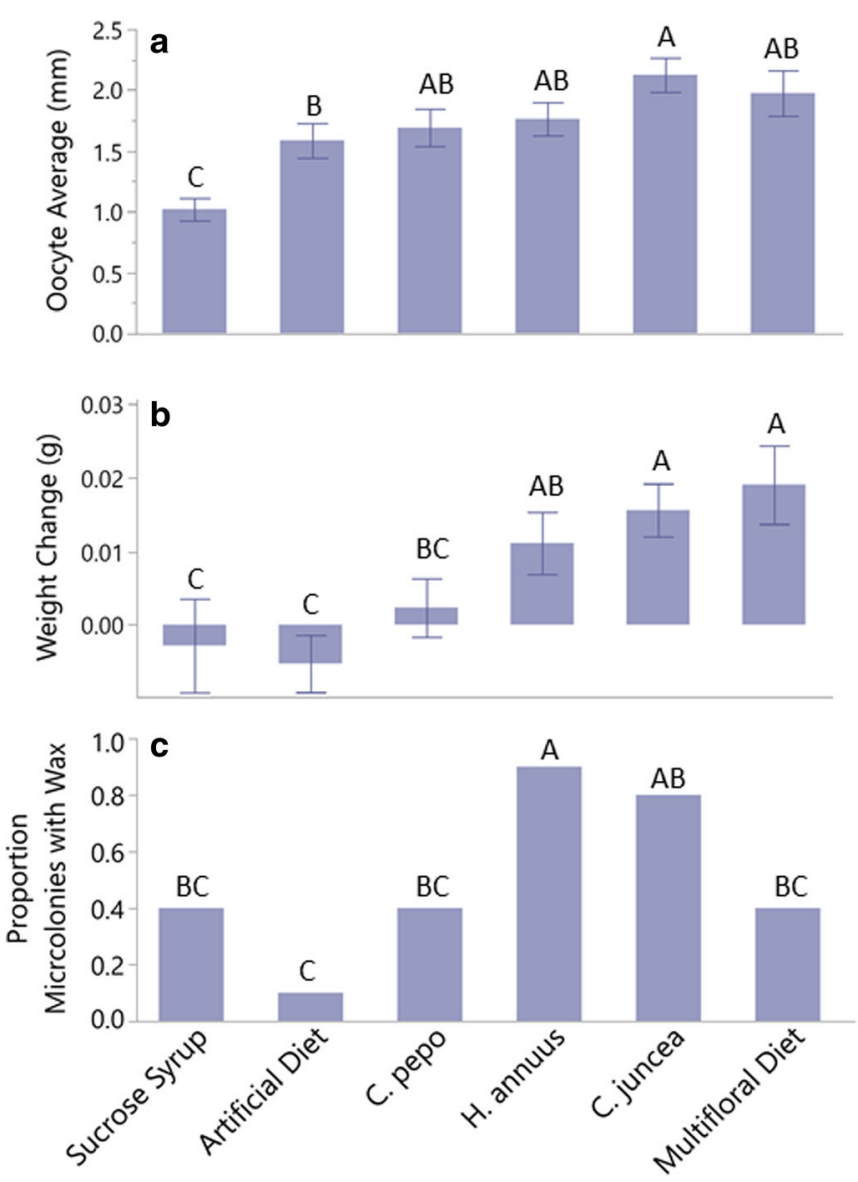

Figure 1. a Average oocyte size $(\mathrm{mm})$ of a $B$. impatiens worker across the six different diet treatments (sucrose syrup, artificial diet, C. pepo, H. annuus, multifloral, C. juncea). Workers were kept in groups of three and limited to a one of six diets over seven days. Data is presented as (mean $\pm \mathrm{SE}$ ); different letters represent statistical differences $(p<0.05)$. b Average weight change per bee $(\mathrm{g})$ across the six different diet treatments (sucrose syrup, artificial diet, C. pepo, H. annuus, multifloral, $C$. juncea). Workers were kept in groups of three and limited to a one of six diets over seven days. Data is presented as (mean $\pm \mathrm{SE}$ ); different letters represent statistical differences $(p<0.05)$. c Proportion of microcolonies (out of total number of microcolonies per dietary treatment) that produced wax structures over the course of 7 days ( $n=10$ for all treatments except the multifloral treatment, $n=5$ for the multifloral treatment). 
(Figures 1a and 2). The covariate of weight change, or weight gain, was positively associated with oocyte size though it was a relatively poor fit $\left(F_{1,150}=19.0, p<0.01, R^{2}=0.11\right)$. The interaction between treatment and weight gain on oocyte size indicates that weight gain alone is not a sufficient predictor of ovary development.

We tested the effect of dietary treatment on weight change, which had a significant effect (Table I; Figure 1b). Bees that consumed artificial diet tended to lose weight, while those fed sucrose syrup alone showed no general weight gain or loss. Weight gain occurred with pollen diet; those fed sunn hemp $(C$. juncea $)$ or the multifloral diet treatment gained the most weight across-seven days, whereas individuals that consumed pumpkin (C. pepo ) pollen gained the least amount of weight (Table I; Figure 1b). We observed that a number of bees consuming pumpkin (C. pepo) (11/27 bees) lost weight (Figure 1b).

We examined each microcolony at the end of the experiment to determine if wax was produced. We found a significant effect of diet treatment on wax production $\left(\chi^{2}=19.6, \mathrm{df}=5, p<0.01\right.$; Table I; Figure 1c). Microcolonies fed sunflower (H. annuus) were significantly more likely to produce wax than microcolonies consuming pumpkin (odds ratio $=13.5 p=0.035$ ), artificial diet (odds ratio $=81 p=0.0032$ ), or sucrose syrup alone (odds ratio $=13.5 p=0.035$ ). Additionally, microcolonies fed sunflower pollen were more likely to produce wax than those consuming the multifloral diet, but not significantly (odds ratio =
$2.25 p=0.0620$ ), which is likely linked to the smaller sample size used.

\section{DISCUSSION}

In our study, we examined the nutritional quality of pollen of floral species available in a lateseason (August-October) pumpkin (Cucurbita реро ) agroecosystem designed to support pollinators in the mid-Atlantic region. We examined ovarian development, weight gain, survival, and wax production in $B$. impatiens microcolonies consisting of three workers. Our results support the hypothesis that different pollen diets, and therefore, the associated differences in some parameters of nutritional quality (i.e. macronutrient concentrations and P:L ratios) correlate with complex differences in weight change, wax production, and ovary development in B. impatiens workers.

Our findings demonstrate that consuming pollen increases adult ovary development in bumble bees (Table I; Figures 1a and 2), which is consistent with numerous other studies linking reproductive performance with pollen consumption (Génissel et al. 2002; Moerman et al. 2015, 2017; Tasei and Aupinel 2008a, b). Overall, there was no clear correlation between P:L ratios of the pollen and rates of ovary development. It is important to note that our analysis did not account for other nutritional factors in pollen (e.g., dietary sterols or amino acids). Furthermore, the P:L ratios of the pollen in our diets only represented a
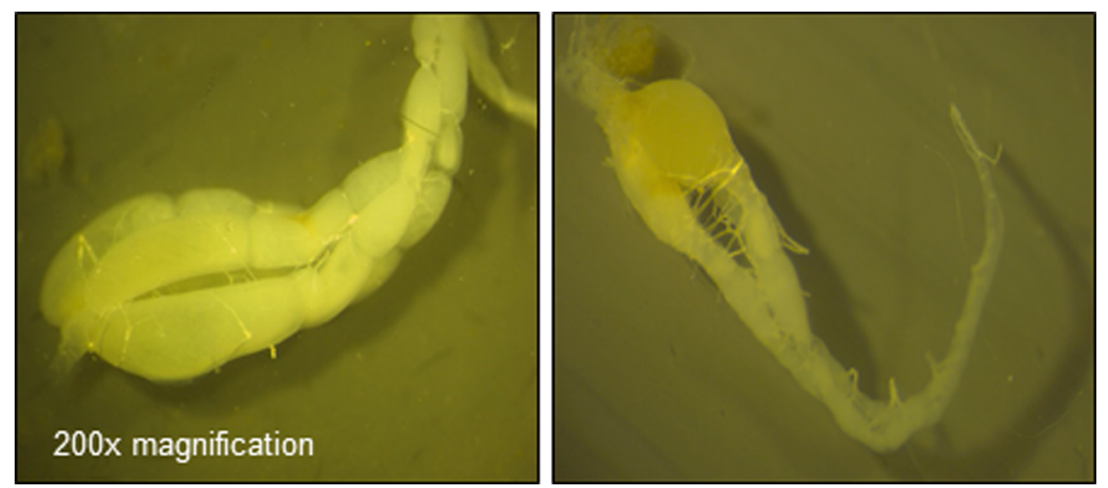

Figure 2. Photographs of Bombus impatiens worker ovaries fed from the multifloral diet (left) versus the sucrose syrup only diet (right). 
limited range of $\mathrm{P}: \mathrm{L}$ ratios present in pollen (Roulston et al. 2000; Vaudo et al. 2015), and are below the range of pollen most preferred by B. impatiens (Vaudo et al. 2016a, b, 2018). To fully explore the relationship between diet and bee reproductive physiology, a larger array of pollens of varying nutritional quality needs to be assessed.

Our examination of $\mathrm{P}: \mathrm{L}$ ratios showed that $\mathrm{P}: \mathrm{L}$ alone could not explain ovarian development. Sunn hemp $(C$. juncea) pollen, which had the highest $P: L$ ratio, and multifloral pollen, which had the lowest, both supported the highest rates of ovary development. However, among the single-source pollens, the higher $\mathrm{P}: \mathrm{L}$ ratio resulted in higher ovary activation, the larger ovary size resulting from multifloral pollen suggests that other micronutrients not assessed in this study may be influencing ovarian development. Several lab studies have demonstrated the benefits of a diverse pollen diet while also considering nutrient composition; microcolonies fed high-quality monofloral diets performed better than those fed low-quality polyfloral diets (Moerman et al. 2017). Thus, it is important for bumble bees (and likely other generalist bees) to have access to both diverse and highquality floral resource patches. Interestingly, diets highest in lipids (i.e. sunflower (H. annuus)) promote wax production but are not necessarily beneficial for reproductive development, suggesting that different macronutrients are necessary for different biological functions, as has been demonstrated in numerous other studies examining the nutritional geometric framework theory (Raubenheimer and Simpson 2018).

Although some mass-flowering agricultural crops are beneficial for pollinators (Westphal et al. 2009), assessing the quality of resources provided in the landscapes surrounding massflowering crops is likely more important. For example, despite the high levels of protein in pumpkin (C. pepo ) pollen (Table I), secondary metabolites and chemical defenses (Tallamy and Krischik 1989) may adversely affect generalist pollinator's health. In our study, individuals who only consumed pumpkin (C. pepo ) pollen averaged very low weight gains, and $39 \%$ of the individuals (11/28) lost weight; the only other diet that caused individuals to lose weight was the artificial diet
(Figure 1b). However, the multifloral diet, which included pumpkin (C. pepo) pollen, resulted in some of the largest oocytes and weight gains (Table I, Figures 1a and 2). Thus, in an agricultural context diverse pollen sources, as represented by our multifloral pollen mixture, can potentially negate the negative effects of pure pumpkin (C. pepo) pollen and lead to healthier local bumble bee populations. Indeed, similar pollen mixing and dilution strategies have been observed in other generalist bees (Eckhardt et al. 2014).

While our study clearly demonstrated the impacts of different pollen diets on the physiology of individual bees, larger-scale studies should be conducted to examine the influence of diverse dietary pollens on bumble bee colonies and across their seasonal life cycle. In addition to incorporating a wider range of pollen diets and nutritional breadth, other approaches can be used to disentangle nutrient allocation, such as pollen substitutes, macronutrient tracking, or detailed body composition analyses (Aguila et al. 2012; Amsalem et al. 2015a). It is important to test the effects of these diets on egg laying, larval development, and overall colony growth for a more comprehensive analysis of pollen nutrition on colony health (Tasei and Aupinel 2008b). However, such experiments would be challenging, as it can be difficult to collect sufficient amounts of fresh pollen directly from non-commercially grown flowers. With large-scale pollen collection or manipulation of pollen macronutrient ratios (see Vaudo et al. 2016a), it would be possible to examine more complex physiological and colony-level responses and parse out the impacts of individual nutrients. Furthermore, it is clear that different bee species (and different pollinators) will likely have distinct nutritional requirements, and thus, similar studies would need to be conducted for multiple species.

Floral enhancement schemes can serve to mitigate the impacts of habitat fragmentation and loss of floral resources in agroecosystems. Developing a framework to identify what makes a resource "high quality" is a necessary first step, in conjunction with identifying the 
nutritional needs across bee species and between life stages. Our work suggests that for $B$. impatiens, the nutritional quality and diversity of the resources available in floral enhancement schemes should be considered during their conception.

\section{ACKNOWLEDGMENTS}

The authors thank Project Integrated Crop Pollination. We thank Laura Russo for providing pollen used in the multifloral diets. We also thank Hannah Balko and Nick Krause for their technical assistance in the field.

\section{AUTHORS' CONTRIBUTION}

EDT: experimental design, performed experiments, data analysis, wrote manuscript.

ADV: conception of experiment, experimental design, data analysis, critical review.

CMG: conception of experiment, experimental design, critical review.

SJF: conception of experiment, data analysis, critical review.

All authors have given final approval to the version being published.

\section{FUNDING INFORMATION}

This material is based upon work that is supported by the National Institute of Food and Agriculture, U.S. Department of Agriculture, under award number 2012-51181-20105, Developing Sustainable Pollination Strategies for U.S. Specialty Crops.

\section{COMPLIANCE WITH ETHICAL STANDARDS}

Conflict of interest The authors declare that they have no conflict of interest.

Examen de la valeur nutritionnelle et des effets de différentes ressources florales dans les agroécosystèmes de citrouilles sur la physiologie des travailleurs de Bombus impatiens .

nutrition du pollen / physiologie des bourdons / récompenses florals / écosystèmes agricoles / microcolonies

Untersuchungen zum Nährwert und zum Effekt unterschiedlicher floraler Bestandteile auf die
Physiologie von Bombus impatiens Arbeiterinnen in Kürbis-Agrarökosystemen

Pollenernährung / Hummel-Physiologie / florale

Belohnung / Agroökosysteme / Minivölker

\section{REFERENCES}

Aguila, J. R., Hoshizaki, D. K., \& Gibbs, A. G. (2012) Contribution of larval nutrition to adult reproduction in Drosophila melanogaster. J. Exp. Biol. 216, 399-406.

Alaux, C., Ducloz, F., Crauser, D., \& Le Conte, Y. (2010) Diet effects on honeybee immunocompetence. Biol. Lett., 6 (4), 562-565.

Amsalem, E., Galbraith, D. A., Cnaani, J., Teal, P. E., \& Grozinger, C. M. (2015a) Conservation and modification of genetic and physiological toolkits underpinning diapause in bumble bee queens. Mol. Ecol., 24 (22), 5596-5615.

Amsalem, E., Grozinger, C. M., Padilla, M., \& Hefetz, A. (2015b) The physiological and genomic bases of bumble bee social behavior. Adv. Insect Physio. (48 ) 37-93.

Artz, D. R., Hsu, C. L., \& Nault, B. (2011) Influence of honey bee, Apis mellifera, hives, hives and field size on foraging activity of native bee species in pumpkin fields. Environ. Entomol. 40 (5), 1144-1158.

Behmer, S. T., \& Nes, W. D. (2003) Insect sterol nutrition and physiology: a global overview. Adv. Insect Physiol, 31, 1-72.

Brodschneider, R., \& Crailsheim, K. (2010) Nutrition and health in honey bees. Apidologie, 41 (3), 278-294.

Cane, J. H. (2016) Adult pollen diet essential for egg maturation by a solitary Osmia bee. J. Insect Physiol., 95, 105-109.

Carvalheiro, L. G., Seymour, C. L., Nicolson, S. W. \& Veldtman, R. (2012) Creating patches of native flowers facilitates crop pollination in large agricultural fields: mango as a case study. J. Appl. Ecol., 49, 1373-1383.

Cnaani, J., Thomson, J.D., \& Papaj D.R. (2006) Flower choice and learning in foraging bumble bees: effects of variation in nectar volume and concentration. Ethology, 112, 278-285.

Crailsheim, K., Schneider, L.H.W., Hrassnigg, N., Bühlmann, G., Broasch, U., et al. (1992) Pollen consumption and utilization in worker honey bees (Apis mellifera carnica ): dependence on individual age and function. J. Insect Physiol.. 38, 409-419.

Di Pasquale, G., Salignon, M., Le Conte, Y., Belzunces, L. P., Decourtye, A. et al. (2013) Influence of pollen nutrition on honey bee health: do pollen quality and diversity matter? PLoS One, 8(8), e72016.

Duchateau, M. J. \& H. H. W. Velthuis. (1989) Ovarian development and egg laying in workers of Bombus terrestris . Entomol. Exp. Appl. 51,199-213

Eckhardt, M., Haider, M., Dorn, S., \& Müller, A. (2014) Pollen mixing in pollen generalist solitary bees: a 
possible strategy to complement or mitigate unfavorable pollen properties? J. Anim. Ecol., 83 (3), 588597.

Frias, B. E. D., Barbosa, C. D., \& Lourenço, A. P. (2016) Pollen nutrition in honey bees (Apis mellifera): impact on adult health. Apidologie, 47 (1), 15-25.

Génissel, A., Aupinel, P., Bressac, C., Tasei, J. N., \& Chevrier, C. (2002) Influence of pollen origin on performance of Bombus terrestris micro-colonies. Entomol. Exp. Appl. 104 (2-3), 329-336.

Goulson, D. (2010) Bumble bees: behavior, ecology, and conservation (No. Ed. 2). Oxford University Press. New York.

Goulson, D., Lye, G. C., \& Darvill, B. (2008) Decline and conservation of bumble bees. Annu. Rev. Entomol., 53, 191-208.

Hendriksma, H. P., \& Shafir, S. (2016). Honey bee foragers balance colony nutritional deficiencies. Behav. Ecol. Sociobiol., 70 (4), 509-517.

Leza, M., Watrous, K. M., Bratu, J., \& Woodard, S. H. (2018) Effects of neonicotinoid insecticide exposure and monofloral diet on nest-founding bumblebee queens. Proc. R. Soc. Lond., 285 (1880).

McGrady (2018) Pollination services, colony abundances and population genetics of Bombus impatiens ), Master Thesis, The Pennsylvania State University, 07/10/ 2018.

Moerman, R., Vanderplanck, M., Roger, N., Declèves, S., Wathelet, B., et al. (2015) Growth rate of bumble bee larvae is related to pollen amino acids. J. Econ. Entomol., 109 (1), 25-30.

Moerman, R., Vanderplanck, M., Fournier, D., Jacquemart, A.-L. \& Michez, D. (2017) Pollen nutrients better explain bumble bee colony development than pollen diversity. Insect Conserv. Divers., 10, 171-179.

Nepi, M., Bini, L., Bianchi, L., Puglia, M., Abate, M. et al. (2011) Xylan-degrading enzymes in male and female flower nectar of Cucurbita pepo . Ann. Bot. 108, 521527.

Nepi, M., Soligo, C., Nocentini, D., Abate, M., Guarnieri, M. et al. (2012) Amino acids and protein profile in floral nectar: much more than a simple reward. Flora, 207 (7), 475-481.

Rasmont, P., Regali, A., Ings, T. C., Lognay, G., Baudart, E., et al. (2005) Analysis of pollen and nectar of Arbutus unedo as a food source for Bombus terrestris (Hymenoptera: Apidae). J. Econ. Entomol., 98(3), 656-663.

Raubenheimer, D., \& Simpson, S. J. (2018) Nutritional ecology and foraging theory. Curr. Opin. Insect. Sci., 27, 38-45.

Regali A \& Rasmont (1995) Nouvelles méthodes de test pour l'évaluation du régime alimentaire chez des colonies orphelines de Bombus terrestris (L) (Hymenoptera, Apidae). Apidologie, 26, 273-281.

Riddell, C. E., \& Mallon, E. B. (2006) Insect psychoneuroimmunology: immune response reduces learning in protein starved bumblebees (Bombus terrestris ). Brain Behav. Immun., 20 (2), 135-138.

Roger, N., Michez, D., Wattiez, R., Sheridan, C., \& Vanderplanck, M. (2017) Diet effects on bumblebee health. J. Insect Physiol., 96, 128-133.

Roulston T.H., \& Cane J.H. (2000) Pollen nutritional content and digestibility for animals. Plant Syst. Evol., $222,187-20$.

Roulston, T.H., Cane, J.H., \& Buchmann, S.L. (2000) What governs protein content of pollen: pollinator preferences, pollen-pistil interactions, or phylogeny? Ecol. Monogr., 70, 617-643.

Ruedenauer, F. A., Spaethe, J., \& Leonhardt, S. D. (2016) Hungry for quality - individual bumblebees forage flexibly to collect high-quality pollen. Behav. Ecol. Sociobiol. 70 (8), 1209-1217.

Schmehl, D. R., Teal, P. E., Frazier, J. L., \& Grozinger, C. M. (2014) Genomic analysis of the interaction between pesticide exposure and nutrition in honey bees (Apis mellifera ). J. Insect Physiol., 71, 177-190.

Shpigler H, et al. (2013) Social influences on body size and developmental time in the bumblebee Bombus terrestris . Behav. Ecol. Sociobiol. 67 (10) 1601-1612

Sibbald, E.D, Plowright, C.M.S. (2013) On the relationship between aggression and reproduction in pairs of orphaned worker bumblebees (Bombus impatiens ). Insect. Soc. 60, 23-30

Sutcliffe, G. H., \& Plowright R. C. (1988) The effects of food supply on adult size in the bumble bee Bombus terricola Kirby (Hymenoptera: Apidae). Can. Entomol., 120, 1051-1058.

Sutcliffe, G.H, \& Plowright, R.C. (1990) The effects of pollen availability on development time in the bumble bee Bombus terricola K. (Hymenoptera: Apidae). Can. J. Zool., 68,1120-1123.

Tallamy, D. W., Krischik, V. A. (1989) Variation and function of cucurbitacins in Cucurbita: an examination of current hypotheses. Am. Nat., 133 (6), 766-786.

Tasei, J. N., \& Aupinel, P. (2008a) Validation of a method using queenless Bombus terrestris micro-colonies for testing the nutritive value of commercial pollen mixes by comparison with queenright colonies. J. Econ. Entomol., 101 (6), 1737-1742.

Tasei, J.-N., \& Aupinel, P. (2008b) Nutritive value of 15 single pollens and pollen mixes tested on larvae produced by bumblebee workers (Bombus terrestris, Hymenoptera: Apidae). Apidologie, 39 (4), 397-409.

Van Handel, E., Day, J.F. (1988) Assay of lipids, glycogen and sugars in individual mosquitoes: correlations with wing length in field-collected Aedes vexans. J. Am. Mosq. Control Assoc., 4 (4), 549-550.

Vanderplanck, M., Moerman, R., Rasmont, P., Lognay, G., Wathelet, B. et al. (2014) How does pollen chemistry impact development and feeding behaviour of polylectic bees? PLoS One, 9 (1), 1-9.

Vaudo, A. D., Tooker, J. F., Grozinger, C. M., \& Patch, H. M. (2015) Bee nutrition and floral resource restoration. Curr. Opin. Insect Sci., 10, 133-141. 
Vaudo, A. D., Patch, H. M., Mortensen, D. A., Tooker, J. F., \& Grozinger, C. M. (2016a) Macronutrient ratios in pollen shape bumble bee (Bombus impatiens) foraging strategies and floral preferences. Proc. Natl. Acad. Sci. U. S. A., 113 (28), E4035-E4042.

Vaudo, A. D., Stabler, D., Patch, H. M., Tooker, J. F., Grozinger, C. M., et al. (2016b) Bumble bees regulate their intake of the essential protein and lipid pollen macronutrients. J. Exp. Biol., 219 (24), 3962-3970.

Vaudo, A. D., Farrell, L. M., Patch, H. M., Grozinger, C. M., \& Tooker, J. F. (2018) Consistent pollen nutritional intake drives bumble bee (Bombus impatiens) colony growth and reproduction across different habitats. Ecol. Evol., 8, 5765-5776.

Westphal, C., Steffan-Dewenter, I. \& Tscharntke, T. (2009) Mass flowering oilseed rape improves early colony growth but not sexual reproduction of bumble bees. J. Appl. Ecol., 46, 187-193.
Wright, G. A., Nicolson, S. W., \& Shafir, S. (2018) Nutritional physiology and ecology of honey bees. Annu. Rev. Entomol. 63, 327-344.

Yerushalmi S, Bodenhaimer S, Bloch G (2006) Developmentally determined attenuation in circadian rhythms links chronobiology to social organization in bees. J. Exp. Biol., 209, 1044-1051

Zarchin, S., Dag, A., Salomon, M., Hendriksma, H. P., \& Shafir, S. (2017) Honey bees dance faster for pollen that complements colony essential fatty acid deficiency. Behav. Ecol. Sociobiol., 71 (12), 172.

Publisher's note Springer Nature remains neutral with regard to jurisdictional claims in published maps and institutional affiliations. 